\title{
Research
}

\section{The Influence of Ethnic Diversity on Social Network Structure in a Common-Pool Resource System: Implications for Collaborative Management}

\author{
$\underline{\text { Michele Barnes-Mauthe }}^{1}, \underline{\text { Shawn Arita }}^{1,2}, \underline{\text { Stewart D. Allen }}^{3}, \underline{\text { Steven A. Gray }}^{l}$ and $\underline{\text { PingSun Leung }}^{1}$
}

\begin{abstract}
Social networks have recently been identified as key features in facilitating or constraining collaborative arrangements that can enhance resource governance and adaptability in complex social-ecological systems. Nonetheless, the effect of ethnicity on social network structure in an ethnically diverse common-pool resource system is virtually unknown. We characterize the entire social network of Hawaii's longline fishery, an ethnically diverse competitive pelagic fishery, and investigate network homophily, network structure, and cross-scale linkages. Results show that ethnicity significantly influences social network structure and is responsible for a homophily effect, which can create challenges for stakeholder collaboration across groups. Our analysis also suggests that ethnicity influences the formation of diverse network structures, and can affect the level of linkages to outside industry leaders, government or management officials, and members of the scientific community. This study provides the first empirical examination of the impact of ethnic diversity on resource user's social networks in the common-pool resource literature, having important implications for collaborative resource management.
\end{abstract}

Key Words: collaborative resource management; common-pool resources; ethnic diversity; fisheries; Hawaii; information exchange; social network analysis

\section{INTRODUCTION}

Social networks have recently been identified as important characteristics of social-ecological systems that can facilitate or constrain collaboration and other key aspects of effective natural resource governance (Bodin and Prell 2011). Social networks, defined as patterns of relationships between individuals or groups, can facilitate information exchange between actors with diverse perspectives and enhance stakeholder cooperation (Crona and Bodin 2006, Isaac et al. 2007). Social networks can also provide stakeholders access to external resources and aid in mobilizing those resources necessary for effective management (Carlsson and Sandström 2008, Newman and Dale 2007). Additionally, social networks have been found to facilitate the establishment of common rules, norms, and sanctions among stakeholders (Dietz et al. 2003, Pretty 2003), and enhance conflict resolution (Hahn et al. 2006, Bodin and Crona 2009).

Despite the positive influence social networks can have on natural resource governance initiatives, not all networks function in the same manner (Bodin and Crona 2009). Social networks can be comprised of various structural patterns with different types of network ties, each with advantages and potential drawbacks depending on the context. For example, empirical studies have shown that social networks with low structural cohesion, particularly those with the existence of various subgroups, can pose challenges to collaboration because of "us-them" attitudes that may develop (Krackhardt and Stern 1988, Borgatti and Foster 2003). In contrast, cohesive networks with a high density of ties have been found to be positively correlated with joint action (Crona and Bodin 2009). However, densely connected networks have also been shown to result in the homogenization of knowledge and experiences (Gray et al. 2012a), which may negatively impact resource governance if attitudes and practices not conducive to managing resources sustainably are compounded throughout the network (Oh et al. 2004, Bodin and Norberg 2005). Thus, understanding the structural pattern of social networks in natural resource systems is important for gaining a more thorough understanding of how social processes may impede or facilitate effective collaborative management and sustainable resource use (Bodin and Prell 2011).

In common-pool resource systems, the structure of resource user's social networks may be particularly important to consider because of the high levels of uncertainty and competition over resource use often inherent in them (Grafton 2005). This can become even more complex when resource users are comprised of ethnically diverse backgrounds with different language capabilities and cultural norms that influence decision making and behaviors. Previous sociological research on social networks has shown that racial and ethnic differences can create strong divides between individuals, which can have substantial implications on the level and quality of information different actors receive, the attitudes and beliefs they form, and the interactions they experience (McPherson et al. 2001). Thus, ethnic diversity among resource users is likely to influence social network

\footnotetext{
${ }^{1}$ Department of Natural Resources and Environmental Management, University of Hawaii at Manoa, ${ }^{2}$ Department of Economics, University of Hawaii at Manoa, ${ }^{3}$ Pacific Islands Fisheries Science Center, NOAA Fisheries
} 
structure, which can affect collaboration and patterns of resource use, yet the role of ethnic diversity on social networks in a common-pool resource system has yet to be examined.

The goal of this study is to contribute to the relatively new field of social networks and natural resource management by analyzing resource user's social networks in an ethnically diverse common-pool resource system. We begin by reviewing recent literature relating to social networks and natural resource management and reconcile this perspective with theory related to ethnic diversity, public goods, and socioeconomic outcomes.

\section{Bonding, bridging, and cross-scale linkages}

Network structure can be affected by three different types of social ties: (1) bonding ties, which involve strong social linkages within groups of like-minded individuals characterized by dense, localized networks; (2) bridging ties, which characterize weaker linkages across somewhat similar, but different groups or social networks; and (3) cross-scale linkages, or linking ties, which refer to ties across incongruent groups or networks at different hierarchical levels (Grafton 2005). Strong ties are particularly relevant in common-pool resource systems because common-pool resources can be augmented or depleted by the level of harvesting, harvesting is often rivalrous, and the ability to exclude outsiders is typically limited (Grafton 2005). Therefore trust, cooperation, and reciprocity, often enriched by strong bonding networks, can be vital in encouraging individuals to observe standards, rules, and sustainable practices, thus decreasing externalities for individual resource users (Grafton 2005, Gray et al. 2012b).

In contrast, bridging ties have the ability to link heterogeneous groups or networks of people into a larger network, which can facilitate access to external resources and diverse knowledge (Crona 2006, Newman and Dale 2007, Sandström and Rova 2010). Key actors forming bridging ties among smaller groups or subgroups may also help to foster trust among heterogeneous actors and may be capable of connecting and mobilizing subgroups toward a common goal, which can advance collaborative processes (Woolcock 2001, Bodin and Crona 2009, Ramirez-Sanchez 2011a).

Cross-scale linkages can be beneficial because they can (1) provide stakeholders increased access to scientific knowledge; (2) facilitate the transfer of local ecological knowledge from the bottom up; (3) help ensure stakeholder interests are represented in the management and policy arena; and (4) facilitate stakeholder understanding and cooperation in regard to management initiatives (Woolcock 2001, Grafton 2005).

Thus, the structure of resource user's social networks can have important implications for collaborative resource management. Nonetheless, there have been relatively few studies on the factors that influence resource user's social networks (but see
Crona and Bodin 2006, Ramirez-Sanchez and Pinkerton 2009, and Ramirez-Sanchez 2011b), and the impact of ethnic diversity among stakeholders on social network structure in terms of collaborative resource management is virtually unknown.

\section{Ethnicity and social structure}

Many studies have shown that ethnic diversity among actors can play a substantial role in influencing social and economic outcomes. For example, empirical socioeconomic research has found that ethnic diversity is generally associated with fragmentation and lower levels of trust across groups (Alesina and La Ferrara 2002, Ruttan 2006). In relation to public goods, ethnic diversity is often associated with a decreased ability to impose social sanctions, which can lead to collaborative failures (Miguel and Gugerty 2005, Baland et al. 2007).

In terms of social networks, previous research has shown that ethnic diversity can create ethnic boundaries (Baerveldt et al. 2004) and enclaves (Portes and Sensenbrenner 1993), and ethnicity has been identified as the number one cause of homophily, wherein individuals tend to associate with others similar to themselves (McPherson et al. 2001). Indeed, numerous studies looking at social structure have found evidence of strong preference for intra-ethnic-group relations (Schofield 1979, 1991, DuBois and Hirsch 1990, Clark and Ayers 1992, Currarini et al. 2009). This ethnic homophily effect is thought to be inflated under conditions of competition (Poteete and Ostrom 2004), which is a typical characteristic of common-pool resource systems (Costello et al. 2008). Indeed, a recent study by Pomeroy et al. (2007) found ethnicity, among other effects, to be a significant determinant of conflict over fisheries resources in Thailand. Though in some cases ethnic diversity among stakeholders has been found to have a negligible impact on cooperation across groups (Varughese and Ostrom 2001), the specific conditions under which this occurs is still poorly understood.

Given the influence of ethnicity on social relationships coupled with the importance of social networks for collaboration in natural resource management, in this paper we explore the relationship between ethnic diversity and social network structure in a competitive common-pool resource system. Specifically, we use common metrics from social network analysis (SNA) and examine network homophily, network structure, and cross-scale linkages to infer characteristics of representation, cooperation, and communication in an ethnically diverse competitive pelagic fishery.

\section{Study area}

Hawaii's longline fishery (HLF) is the dominant commercial fishery sector in the Hawaiian Islands harvesting mainly bigeye tuna (Thunnus obesus), yellowfin tuna (Thunnus albacares), and swordfish (Xiphias gladius; Fig. 1). In 2011 there were 129 active vessels that completed 1388 fishing trips (NOAA 2012) generating approximately $\$ 76$ million in 
revenue (WPacFIN 2012). Though Hawaii has a historically diverse multicultural background (see Nordyke 1989, Haas 1998), the HLF is dominated by three distinct ethnic groups: Korean-American fishers (K-A), Vietnamese-American (VA) fishers, and Euro-American (E-A) fishers (Allen et al. 2013). Though Asian-Americans make up the majority of the population in Hawaii, we classify V-A and K-A fishers separately because the majority of them are first generation immigrants and speak limited English, the dominant language of Hawaii. This classification is in line with previous research (Allen and Gough 2006, 2007, Allen et al. 2013) and was corroborated by fishers (see Appendix 1). E-A fishers largely consist of individuals from the mainland U.S. (Allen et al. 2013) whose native language is English, and are therefore considered the locally dominant ethnic group because they make up 25\% of Hawaii's population, compared with only $1.7 \%$ Korean and $0.5 \%$ Vietnamese according to the $2011 \mathrm{U}$. S. Census estimates (U.S. Census Bureau 2012).

Fig. 1. Map of the study area identifying the range of Hawaii's longline fleet. Longline fishers are restricted from fishing within 50-75 nm of Hawaii's coastline, and typically fish both within and outside of the United States' Exclusive Economic Zone (EEZ) bordering the Hawaiian Islands.

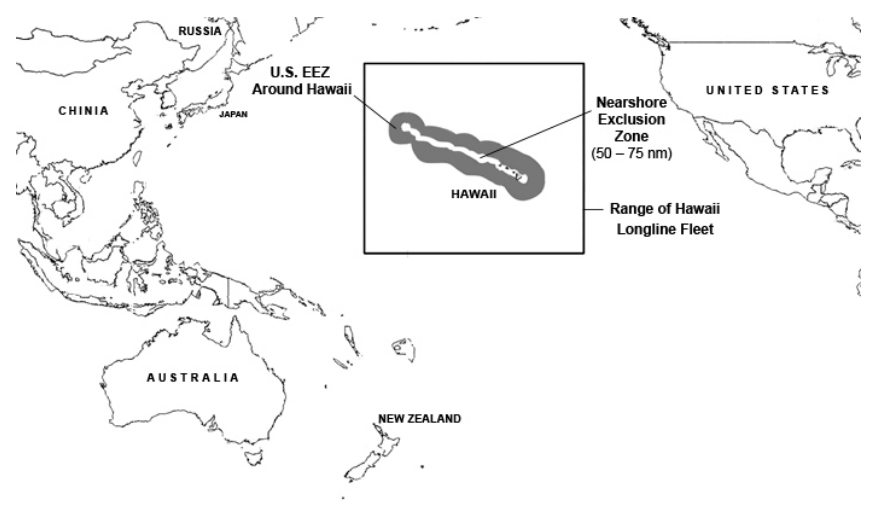

The HLF is under the jurisdiction of the U.S. MagnusonStevens Act (NOAA 2006) and is governed by institutional top-down management that includes participation input by fishers (details here: http://www.wpcouncil.org/pelagic/ Pelagics\%20FMP.html). As a limited entry fishery regulated by a total allowable catch (TAC) on bigeye tuna, a sea turtle bycatch cap, area closures, gear restrictions, onboard observers (100\% coverage for shallow set swordfish lines, $20 \%$ coverage for deep set tuna lines), mandatory logbook and vessel monitoring systems, and numerous other restrictions, the HLF is considered well regulated. However, management still suffers shortcomings; enforcement is costly and not always effective (Allen and Gough 2007, Wilson 2009). Also, there are still some concerns over bycatch of some species (Davies 2012, Kubota 2012), and HLF fishers face growing social and economic impacts from increased competition and regulation (Pan et al. 2001, Allen and Gough 2006, 2007, Allen et al. 2013). Moreover, although U.S. fisheries management is largely built around participation, there are criticisms (McCay and Jentoft 1996) and it has been argued that management of the HLF lacks adequate collaboration and representation among stakeholders given their cultural and geographic isolation (Allen and Gough 2007). Therefore, understanding the degree of collaboration and representation among fishers by way of SNA may provide insight into the level of cooperation among users, which has previously been associated with more sustainable, equitable, and efficient management outcomes (Ostrom 1990, Dietz et al. 2003, Rova 2004, Pinto De Silva and Kitts 2006, Marín and Berkes 2010).

\section{METHODS}

The primary methodology employed in this study was SNA, a quantitative method that uses sociograms and graph theory to analyze social relationships. To obtain the social network data, we developed a structured survey (see Appendix 1) in which primary decision makers were asked to nominate at least 5 , but up to 10 individuals in the HLF with whom they shared useful information regarding different aspects of fishing that they felt was valuable for their fishing success. We defined primary decision makers as vessel owners and captains and they are collectively referred to as fishers throughout this paper. The survey was pretested with fishers in each ethnic group to reduce misinterpretation caused by cultural differences and to diminish potential bias in data collection, after which data was collected for a total of nine months beginning in May 2011. While administering surveys, fishers often spoke openly and at length about different aspects of collaboration and fishery management, which was recorded as notes by field researchers. Acknowledging that this data was collected in an informal and unstructured manner, we incorporate some fisher's qualitative comments into our discussion to add insight to our results.

Basic network characteristics, such as number of actors, total and mean number of ties, indegree (\# of ties identified going to each actor), and outdegree (\# of ties going from each actor), were analyzed for the entire HLF network and for each ethnic community of fishers.

\section{Network homophily}

To examine network homophily we employ three basic network measures: component analysis, ANOVA density model of variable homophily, and relational contingency table analysis.

\section{Component analysis}

This analysis identifies the number of networks in the dataset that are not connected to each other (Hanneman and Riddle 2005). If a network contains completely separate components, it would be an example of the most extreme case of homophily if actors were grouped by a specific attribute, such as ethnicity. 


\section{ANOVA density model of variable homophily}

This model tests the likelihood that the density of ties within each group defined by a particular attribute differs from all ties that are not within groups (Hanneman and Riddle 2005). Density is a measure of the proportion of ties present in a network to all possible ties in a network and ranges from 0 , if there are no ties present, to 1, if all possible ties are present (Hanneman and Riddle 2005). We examine homophily in the following attributes: ethnicity, title, age, education, and experience.

\section{Relational contingency table (RCT) analysis}

RCT analysis determines the ratio of measured versus expected ties within and between groups, where the expected number of ties equals the number of ties expected by chance alone in a network of equal size and number of ties under a model of independence (Hanneman and Riddle 2005). We use RCT analysis to test the observed/expected tie ratios both within and between ethnic groups.

\section{Network structure}

Building on work from Ramirez-Sanchez and Pinkerton (2009), we adopt Crowe's (2007) framework for conceptualizing community networks by examining $k$-cores and cutpoints to categorize each network as complete, coalitional, or bridging (Fig. 2).

Fig. 2. Example of a complete, coalitional, and bridging network classified by Crowe's (2007) framework for analyzing community network structures, adapted from Ramirez-Sanchez and Pinkerton (2009).

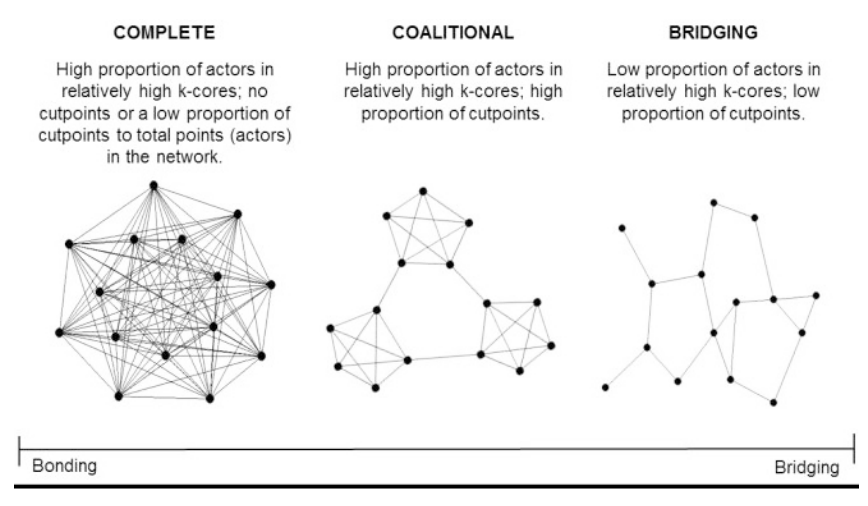

K-core analysis

Employed to determine the level of cohesion in a community network, $k$-core analysis identifies parts of the network that form subgroups in a way that each member of the subgroup is connected to at least $k$ number of other actors in the subgroup. The value of $k$ for each group is determined by finding the maximum amount of actors whom each actor accesses for information, and the lowest reported value of $k$ is used to facilitate comparisons across groups (Crowe 2007).

\section{Blocks and cutpoints}

Used as an indicator of bridging, cutpoints are an actor in a network whom, if removed, would fragment the network into two or more subnetworks, termed blocks. We examine the proportion of cutpoints to total points in each network as an indicator of structural holes, or weakness in the network (Hanneman and Riddle 2005).

\section{Cross-scale linkages}

To examine the level of cross-scale linkages to outside industry leaders, government or management officials, and members of the scientific community for each ethnic community of fishers, we again investigate values calculated by the RCT analysis. Though some actors within each fishing community also classify as industry leaders, for example, a vessel owner who also runs a supply store, we highlight linking ties to actors outside of the three identified fishing communities to whom all HLF fishers potentially have equal access.

All data was analyzed in UCINET6's suite of social network programs (Borgatti et al. 2002), and SPSS Version 20. Network data was visualized in NetDraw (Borgatti 2002).

\section{RESULTS}

Our response rate was $91.2 \%$ for the entire fishery (145 of 159 fishers); $93.3 \%$ for $\mathrm{V}-\mathrm{A}$ fishers (70 of 75); $89.7 \%$ for $\mathrm{E}-\mathrm{A}$ fishers (52 of 58); and $88.5 \%$ for K-A fishers (23 of 26). Though there were a total of 14 fishers who did not participate in the survey, nine of them were identified by at least one but typically a handful of other fishers, making it possible to infer their network, whereas the other five were not identified. Thus, we treated our data as the population, classifying the five actors not identified as isolated fishers. The entire HLF network includes all ties (either valuable or very valuable; see Appendix 1) and actors identified by respondents (Fig. 3). Fisher's ethnic community networks can be found in Figs. 4 (E-A network), 5 (K-A network), and 6 (V-A network).

Basic network characteristics are presented in Table 1. In the entire HLF network, fishers had an average of 9.28 ties per actor, where all ties reported by respondents were considered. E-A fishers and K-A fishers averaged 6.19 and 6.09 ties per actor, respectively. V-A fishers had a significantly higher average at 12.74 ties per actor. As shown in Fig. 7, indegree and outdegree followed a similar pattern, in which both the EA and K-A means were not statistically different. V-A fishers, on the other hand, had significantly higher means for both indegree and outdegree.

\section{Network homophily}

Results of the component analysis (Table 1) showed that all networks formed a single component, meaning no subgroup 
Table 1. Summary of group level network characteristics.

\begin{tabular}{|c|c|c|c|c|}
\hline & Entire HLF & E-A & $\mathrm{K}-\mathrm{A}$ & $\mathrm{V}-\mathrm{A}$ \\
\hline \multicolumn{5}{|l|}{ Network data } \\
\hline Total actors & 179 & 60 & 25 & 77 \\
\hline Total no. of ties & 895 & 189 & 73 & 542 \\
\hline Mean ties per actor & 9.28 & $6.19^{\dagger}$ & $6.04^{\dagger}$ & 12.74 \\
\hline No. of components & 1 & 1 & 1 & 1 \\
\hline Isolated actors & 5 & 1 & 0 & 0 \\
\hline \multicolumn{5}{|l|}{ Indicators of network cohesion } \\
\hline Largest $k$-core & 8 & 4 & 4 & 8 \\
\hline No. of actors in largest $k$-core & 48 & 34 & 16 & 48 \\
\hline Proportion in 4-core and higher & 0.75 & 0.58 & 0.64 & 0.99 \\
\hline \multicolumn{5}{|l|}{ Indicators of structural holes } \\
\hline No. of cutpoints & 10 & 7 & 0 & 1 \\
\hline No. of blocks & 20 & 11 & 1 & 2 \\
\hline Proportion of cutpoints to total points & 0.06 & 0.09 & 0.00 & 0.01 \\
\hline Estimated network configuration & Coalitional & Bridging & Complete/ Bonding & Complete/ Bonding \\
\hline
\end{tabular}

${ }^{\dagger}$ Describes homogenous subsets using the least significant difference (LSD) \& Tukey test at a $>1 \%$ level of significance.

Fig. 3. Network configuration of all relations identified by Hawaii's longline fishers, referred to as the entire HLF network. Nodes (representing actors) with the smallest path lengths to each other are placed closest together in the graph by an algorithm that uses iterative fitting. $\mathrm{E}-\mathrm{A}=$ EuroAmerican, V-A = Vietnamese-American, K-A = KoreanAmerican.

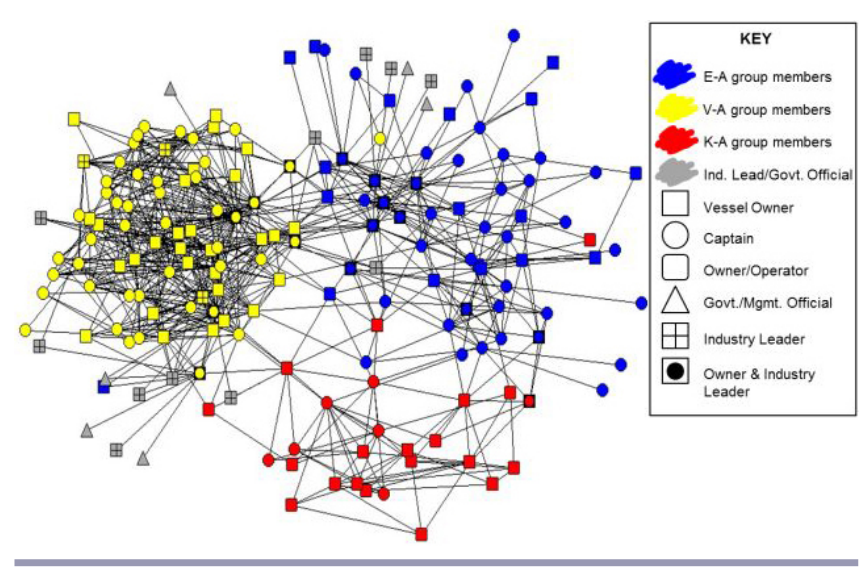

of fishers was completely isolated from the rest. In the entire HLF network there were five isolated fishers, whereas in the E-A community there was one; however, isolated actors were not considered in the group analyses, which is consistent with previous research (Crowe 2007).

Results of the ANOVA density model of variable homophily for each of the selected attributes are presented in Table 2. A dataset containing respondent's only $(91.2 \%$ of the total population) was used to ensure there was no missing attribute data. Densities within groups were converted to a percentage for ease of display.
Table 2. Density of ties by individual attribute (ethnicity, education, experience, age, and title) for all respondents. Densities marked with an $*$ indicate significance at the $5 \%$ level according to the ANOVA test of variable homophily model.

\begin{tabular}{lc}
\hline \hline Category (n) & Density \\
\hline Ethnicity & \\
E-A (47) & $8^{*}$ \\
K-A (22) & $13^{*}$ \\
V-A (70) & $10^{*}$ \\
Education & \\
Elementary School or less (50) & $9^{*}$ \\
High School (48) & 4 \\
Some College (25) & 5 \\
Bachelor's Degree or Higher (16) & 6 \\
Experience Indicator $\dagger$ & \\
1-25 (11) & 5 \\
26-50 (31) & 4 \\
$51-75$ (70) & $7^{*}$ \\
$76-100(20)$ & $7^{*}$ \\
100+ (7) & 2 \\
Age & \\
$25-34(8)$ & 4 \\
$35-44(21)$ & 4 \\
$45-54(49)$ & $7^{*}$ \\
$55-64(48)$ & 4 \\
65+ (13) & 5 \\
Title & \\
Owner (24) & 5 \\
Captain (66) & 4 \\
Owner/Operator (34) & 5 \\
Own/Ind. Leader (15) & $12^{*}$ \\
\hline
\end{tabular}

"Experience Indicator is equal to the sum of experience fishing (in years), years living in Hawaii, and years in the HLF. 
Fig. 4. Network configuration of ties within the EuroAmerican (E-A) community. Nodes (representing actors) with the smallest path lengths to each other are placed closest together by an algorithm that uses iterative fitting.

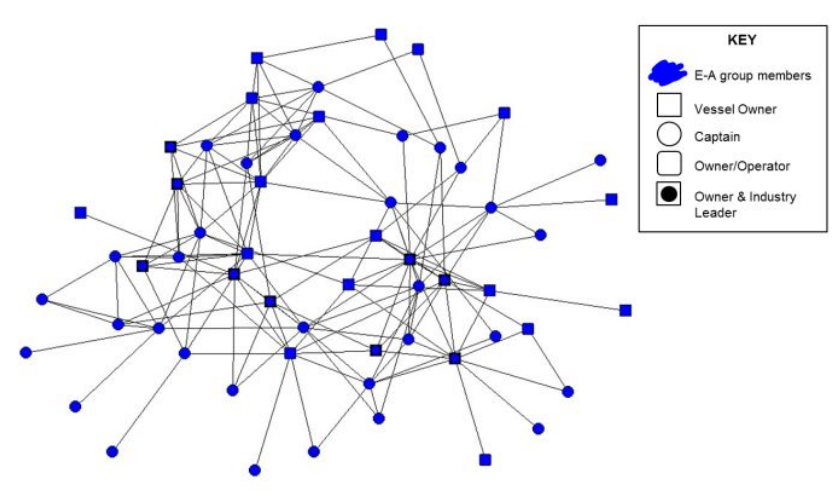

Fig. 5. Network configuration of ties within the KoreanAmerican (K-A) community. Nodes (representing actors) with the smallest path lengths to each other are placed closest together by an algorithm that uses iterative fitting.

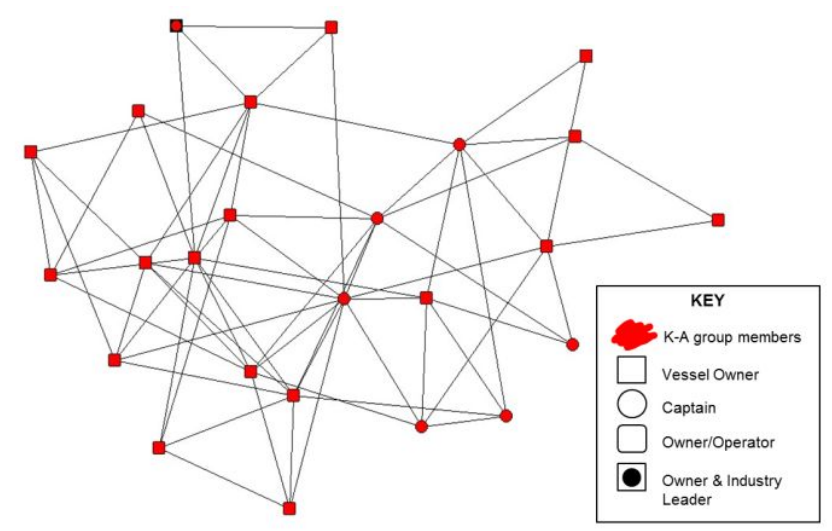

Ethnicity appeared to be the strongest factor influencing fisher's networks, with all of the within group densities for ethnicity being significant. According to the ANOVA model, results also suggested homophilic tendencies within groups for fishers in the elementary school or less category, the 51-75 and 75-100 experience indicator categories, the 45-54 age group, and the owner/industry leader title category. However, none of these attributes displayed significant homophily in all categories besides ethnicity.

Table 3 shows the RCT analysis results for the entire HLF network as the observed/expected ratios for both within and between group ties by ethnicity. Along with a much higher ratio of observed/expected ties within ethnic groups, there were significantly fewer ties between ethnic communities than would be expected under a model of independence. Strikingly, there were no ties to the K-A community originating from the V-A community, while the observed/expected ratio from KA fishers to V-A fishers was only 0.11 .

Fig. 6. Network configuration of ties within the Vietnamese-American (V-A) community. Nodes (representing actors) with the smallest path lengths to each other are placed closest together by an algorithm that uses iterative fitting.

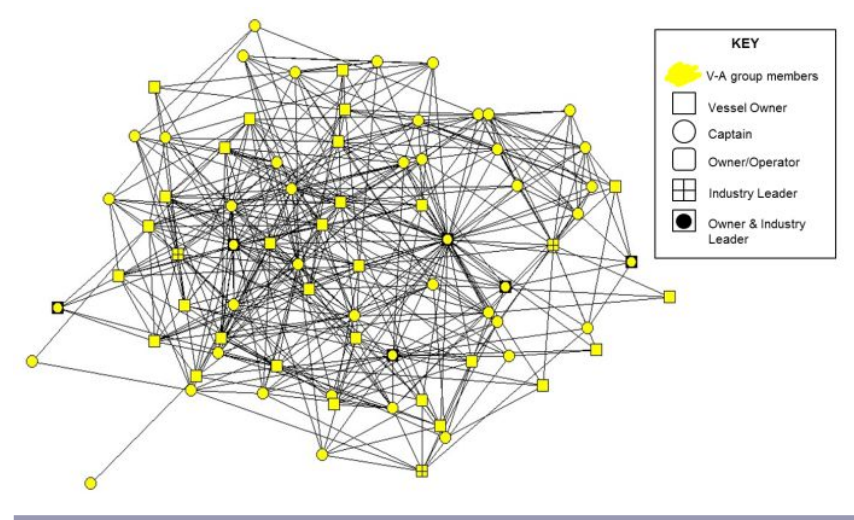

Fig. 7. Normalized outdegree and indegree boxplots for each ethnic community of fishers. E-A = Euro-American, $\mathrm{K}-\mathrm{A}=$ Korean-American, $\mathrm{V}-\mathrm{A}=$ Vietnamese-American.
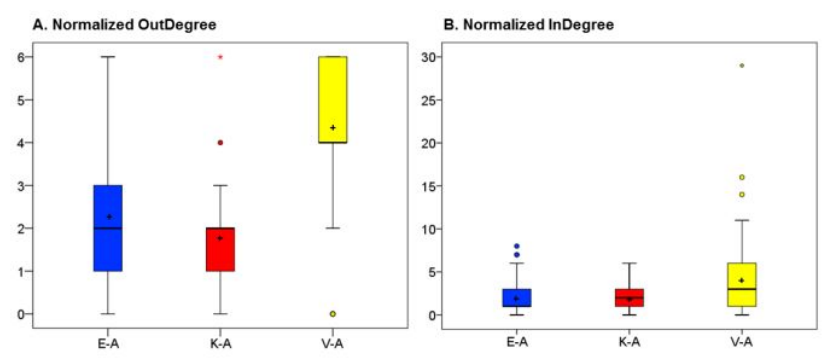

\section{Network structure}

Results of the $k$-core and cutpoint analyses as well as the estimated network configuration for each community can be found in Table 1. The entire HLF network was classified as a coalitional structure because of the observed division along ethnic lines (Fig. 3) as well as the moderate rate of cutpoints (0.06). Though the entire HLF network had a high order of $k$ core $(k=8)$, which was an indicator of network cohesion, all of the 48 fishers in this order were from the V-A community (see the V-A community $k$-core results). 
Table 3. Relational contingency table (RCT) analysis results by ethnicity on all identified Hawaii's longline fishery (HLF) ties. Values are reported as the proportion of observed vs. expected number of ties within and between groups, where a value of 1.00 represents the expected number of ties. Values in bold indicate a higher proportion of ties than would be expected in a network of the same size and number of ties under a model of independence.

\begin{tabular}{lllll}
\hline \hline & & & Ind. Leaders/Govt. \& Mgmt. Officials/Scientific Community \\
\hline E-A & E-A & K-A & V-A & 0.35 \\
K-A & $\mathbf{1 . 9 1}$ & 0.37 & 0.13 & 0.08 \\
V-A & 0.07 & $\mathbf{4 . 0 0}$ & 0.11 & 0.98 \\
\hline
\end{tabular}

The E-A community was classified as a bridging structure (Fig.4), whereas the K-A community (Fig. 5) and the V-A community (Fig. 6) were classified as complete/bonding structures. The difference between the bonding and bridging classification was most obvious when comparing the E-A and V-A networks. The E-A community (Fig. 4) had only $58 \%$ of its members in the 4-core and higher order, whereas the V-A community (Fig. 6) had 99\%. Furthermore, the E-A community had 7 cutpoints and 11 blocks; if these 7 actors were removed from the E-A community, the E-A network would be fragmented into 11 subnetworks. The V-A community only had 1 cutpoint and 2 blocks. Comparatively, the K-A community (Fig. 5) had no identifiable cutpoints, which was a major factor in its classification.

\section{Cross-scale linkages}

The results concerning cross-scale linkages can be found in the final column of Table 3 as the ratio of observed vs. expected number of ties between each ethnic community of fishers and industry leaders, government or management officials, and members of the scientific community. K-A fishers reported $8 \%$ of ties of this nature that one would expect under a model of independence, whereas E-A fishers reported 35\%, and VA fishers reported $98 \%$.

\section{DISCUSSION}

Our network analysis revealed that no group of fishers was completely fragmented or isolated from any other group; however, a homophily effect was clearly apparent, with ethnicity being the most significant factor over all other attributes. We found that E-A fishers appeared to have a bridging network structure; K-A and V-A fishers a bonding network structure; while the entire HLF network appeared more bridging/coalitional. V-A fishers reported most ties per capita as well as the highest level of cross-scale linkages to industry leaders, government or management officials, and members of the scientific community. E-A fishers reported a lower level of cross scale linkages than expected, while K-A fishers reported only one tie to an outside industry leader.

\section{Ethnic homophily and bridging ties}

Analogous to our findings (Tables 2, 3), ethnic homophily has been identified by many previous social and economic studies (e.g., Schofield 1979, 1991, DuBois and Hirsch 1990, Clark and Ayers 1992, Currarini et al. 2009). This preference for within group relations may be explained by the social identity theory (Tajfel and Turner 1979), in which individuals have a sense of group belonging with respect to cultural norms, values, and traditions.

In a resource governance context, this division of actors can present challenges, particularly for stakeholder collaboration across groups. Homophily in networks can affect the information different actors receive and the attitudes and beliefs they form (McPherson et al. 2001), which in turn can influence their decisions and actions regarding resource use and extraction, rule compliance, adherence to norms, and cooperation (Ostrom et al. 1994). Moreover, group identities can cause individuals to accentuate their differences with others rather than their similarities, which can augment conflict (Baerveldt et al. 2004). Indeed, previous research on the HLF found that the three ethnic communities of fishers demonstrate different fishing practices, exhibit different attitudes toward fishery management and regulations, and lack trusting relationships across groups (Allen et al. 2013). Further, while collecting data it was not uncommon for fishers to speak openly about fishers from different ethnic backgrounds as being part of a separate group of actors altogether, signifying the existence of an "us-them" attitude (Krackhardt and Stern 1988, Borgatti and Foster 2003). This lack of cohesion and trust across groups may substantially reduce the ability of HLF fishers to mobilize and agree on and enforce social norms, which are key aspects of collaborative resource governance.

Despite this division, our results showed that ties bridging ethnic communities in the HLF do exist (Fig. 3). These ties may help to build trust across ethnic divides and bring subgroups together behind a common goal under the right circumstances (Bodin and Crona 2009). However, actors occupying central positions between subgroups may also impede collaboration because they may be unaware of their position between subgroups or uninterested in fostering joint action (Bodin and Crona 2009). Thus, identifying these actors and bringing them into the decision making process is likely to benefit the long-term sustainability and adaptability of the 
resource system, which can be classified as a "network intervention' (Valente 2012). These central actors may be able to influence understanding and cooperation among diverse resource users in regard to governance initiatives, while also aiding in the dissemination of technological and scientific information. This type of collaboration would also help to ensure that resource user's interests are represented in the management arena, which may further influence cooperation and participation in resource planning and management (Prell et al. 2008).

Though our analysis focused primarily on ethnic network homophily, it is important to note that our results also revealed homophilic tendencies within the owner/industry leader category (Table 2). This may also have important implications for management because vessel owners/industry leaders are likely to be key players and important sources of information for other resource users. Though characterizing key actors in the network is outside the scope of the current study, future research could seek to examine the agency, power, and influence of central actors and their potential for facilitating or hindering joint action and collaboration across ethnic groups, which would build on other similar inquiries (e.g., Crona and Bodin 2006, Prell et al. 2011, Ramirez-Sanchez 2011a, García-Amado et al. 2012). Although our analysis looked at ethnicity and other attributes separately, future research could also seek to employ social network modeling methods that may examine these and other effects jointly (see Snijders et al. 2006).

\section{Ethnic group structure and social capital}

Both K-A and V-A fishers appeared to have a bonding group network structure, though results showed that the V-A community was more cohesive (Table 1, Fig. 6). This is consistent with a previous study done on social proximity by Romani (2003), which found that ethnic minority groups are more likely to exchange high levels of information within their communities.

Derived from the theory of embeddedness (Granovetter 1985), cohesive bonding networks are sometimes referred to as a type of social capital lubricated by bounded solidarity, reciprocal interactions, and trust, in which norms, rules, and sanctions are likely to be established (Portes and Sensenbrenner 1993, Pretty 2003). The circumstance of "foreignness" is argued to be a key source of this type of social capital among immigrants (Portes and Sensenbrenner 1993). Indeed, previous ethnographic research on the HLF has found that V-A fishers typically demonstrate strong kinship and solidarity within their community, with many immediate and extended family members owning and/or working on a number of vessels together, and assisting others when needed (Allen and Gough 2006, Allen et al. 2013). Coupled with our results here, it appears that a high level of social capital exists within the VA community. However, previous research also suggests that this community cohesion may be weakened by outside impacts; V-A fishers reported a feeling of fragmentation within their community after the temporary swordfish fishery closure in 2001, which had tremendous social and economic impacts on the community (Allen and Gough 2006).

Though less cohesive than the V-A network, results showed that K-A fishers also form a single, bonding network (Table 1, Fig. 5). Though this result suggests that the K-A community may function in a manner similar to the V-A community, previous research on the HLF found a strong divide among KA fishers and a general feeling of low solidarity (Allen et al. 2013). One potential explanation for the incongruity in our findings compared with previous research is that many K-A fishers recently exited the fishery (observed while collecting data), which may have caused a social reorganization. In contrast, our results suggest that the E-A community reflects a bridging network structure that is less tightly bound together (Table 1, Fig. 4), which was hypothesized by previous research (Allen et al. 2013).

\section{Cross-scale linkages: connecting a broader world}

$\mathrm{V}$-A fishers reported a significantly higher proportion of crossscale linkages than both other groups in our analysis (Table 3 ). This result differs from previous work that found that ethnic minority groups tend to have less access to extension services than the locally dominant ethnic group (i.e., Romani 2003). Though here we focused primarily on ethnic dominance relating to proportion of the local population and language capabilities, ethnic dominance can also be influenced by various social and political processes (Waring 2011). Thus, our results regarding cross-scale linkages are particularly intriguing in this case because members of the E-A community rather than the V-A community occupy the majority of leadership positions in the Hawaii Longline Association (HLA), which represents HLF fishers in the governance arena. Although some members of the E-A community reported having ties to HLA officials as well as supply store owners, gear and technology experts, fish auction officials, and government or management officials, many of these ties were identified by only a single E-A fisher. Additionally, the majority of linking ties in the E-A community were identified by only two fishers who themselves also classify as industry leaders (Fig. 3). In contrast, several vessel owners, captains, as well as vessel owners/industry leaders in the V-A community reported similar ties to the same type of actors listed above, but also identified ties to members of the coast guard, customs/border protection officials, and crew agents, and in many cases, ties to these actors were identified by more than one V-A fisher. One possible explanation for this is that $\mathrm{V}$-A fishers have more ties per capita than E-A and K-A fishers (Fig. 7). Another potential explanation is that although the Vietnamese represent an ethnic minority in Hawaii, V-A fishers currently make up the majority in the HLF. A critical question may be whether ethnic dominance at the local level 
or at the system level more distinctly influences the development of, or access to cross-scale linkages (Waring 2011).

$\mathrm{K}$-A fishers reported solely one tie to an industry leader outside of their ethnic community (Fig. 3), which suggests that K-A fishers may be somewhat marginalized from key actors involved in decision making and that their interests may not be adequately represented in the management and policy arena. Also, the lack of cross-scale linkages suggests K-A fishers may have trouble accessing technological and scientific information and resources (Grafton 2005).

\section{CONCLUSION}

Effective management requires an understanding of not only the biological and ecological characteristics of complex social-ecological systems, but also the social aspects of the system. Previous literature has not adequately assessed the role of ethnic diversity on social networks in common-pool resource systems. This study quantitatively shows that ethnic diversity can have a significant impact on network structure and cross-scale linkages, which is likely affecting the potential for collaboration and the overall adaptability of the system.

Though our study was conducted on a single common-pool resource system, we believe that our results are generalizable to other natural resource settings. Our analysis suggests that ethnicity may be responsible for the formation of diverse network structures among resource users. The bonding nature of ethnic minority groups found here suggests that they may depend more on information sharing within their groups, which may help to decrease externalities by building trust and encouraging reciprocity within their community (Grafton 2005, Prell 2009). Cohesive bonding networks and social capital within communities can also lead to successful resource management by helping to establish social norms (Gutiérrez et al. 2011); however, normative attitudes in bonding communities, which may not be conducive to managing resources sustainably, may also be difficult to change (Ehrlich and Levin 2005). Moreover, having a high level of bonding ties may also be responsible for the homogenization of knowledge and experiences, which can negatively impact the ability to adapt to environmental change (Bodin and Crona 2009).

The flow of important scientific information such as knowledge on the state of the resource or technological innovation concerning new sustainable extraction strategies can also be highly impacted by diverse network structures. Therefore managers may need to consider more adequately the role of ethnic diversity among resource user's social networks when considering new management options or attempting to disseminate information because reaching different ethnic communities may require alternative strategies. Because our results show that ethnicity may also play a role in the level of cross-scale linkages to which resource users have access, it may be advantageous for actors in decision making positions to take steps to ensure that ties exist between all resource user groups and the decision making body. This can enhance participation while helping to ensure resource users are represented in the management arena and provided access to resources and scientific knowledge. Reaching this level of engagement may also help to increase the rate of adoption of sustainable practices and facilitate understanding and cooperation among resource users in regard to management and policy initiatives, generally having a positive effect on long-term sustainability.

We live in an increasingly globalized world where ethnic diversity among stakeholders is not limited to this case. As this study found, ethnic barriers may be substantial obstacles to collaboration. Further research could seek to identify the instances that overcome these barriers and explore how such bridging across ethnically or culturally diverse social groups could be enhanced.

Responses to this article can be read online at: http://www.ecologyandsociety.org/issues/responses. $\mathrm{php} / 5295$

\section{Acknowledgments:}

We would like to thank the Pelagic Fisheries Research Program for funding support; our hardworking translators Sunny Bak and Jennifer Tran; and all of the fishers who participated in this study. We also thank Chris Malkus for his graphic design expertise. Lastly, we would like to acknowledge our reviewers, who provided thoughtful and constructive comments that we believe greatly strengthened our work.

\section{LITERATURE CITED}

Alesina, A., and E. La Ferrara. 2002. Who trusts others? Journal of Public Economics 85(2):207-234. http://dx.doi. org/10.1016/S0047-2727(01)00084-6

Allen, S. D., and A. Gough. 2006. Monitoring environmental justice impacts: Vietnamese-American longline fishermen adapt to the Hawaii swordfish fishery closure. Human Organization 65(3):319-328. [online] URL: http://sfaa. metapress.com/link.asp?id=bcpx6u86wc6p8dtp

Allen, S., and A. Gough. 2007. Hawaii longline fisherman's experiences with the observer program. NOAA Technical Memorandum NMFS-PIFSC-8. National Marine Fisheries Service, Honolulu, Hawaii, USA. [online] URL: http://www. pifsc.noaa.gov/tech/NOAA Tech Memo PIFSC 8.pdf

Allen, S., A. Gough, and Y. Swimmer. 2013. Human dimensions of bycatch reduction strategies: five case studies from the Hawaii longline fleet. Pacific Islands Fisheries 
Science Center: National Marine Fisheries Service, Honolulu, Hawaii, USA, in press.

Baerveldt, C., M. A. J. Van Duijn, L. Vermeij, and D. A. Van Hemert. 2004. Ethnic boundaries and personal choice. Assessing the influence of individual inclinations to choose intra-ethnic relationships on pupils' networks. Social Networks 26:55-74. http://dx.doi.org/10.1016/j.socnet.2004.01.003

Baland, J., P. Bardhan, and S. Bowles, editors. 2007. Inequality, cooperation, and environmental sustainability. Princeton University Press, Princeton, New Jersey, USA.

Bodin, Ö., and B. I. Crona. 2009. The role of social networks in natural resource governance: what relational patterns make a difference? Global Environmental Change 19(3):366-374. http://dx.doi.org/10.1016/j.gloenvcha.2009.05.002

Bodin, Ö., and J. Norberg. 2005. Information network typologies for enhanced local adaptive management. Environmental Management 35(2):175-193. http://dx.doi. org/10.1007/s00267-004-0036-7

Bodin, Ö., and C. Prell, editors. 2011. Social networks and natural resource management: uncovering the social fabric of environmental governance. Cambridge University Press, Cambridge, UK. http://dx.doi.org/10.1017/CBO9780511894985

Borgatti, S. P. 2002. NetDraw: graph visualization software. Harvard, Cambridge, Massachusetts and Analytic Technologies, Lexington, Kentucky, USA.

Borgatti, S. P., M. G. Everett, and L. C. Freeman. 2002. UCINET 6 for Windows: software for social network analysis. Harvard, Cambridge, Massachusetts and Analytic Technologies, Lexington, Kentucky, USA.

Borgatti, S. P., and P. C. Foster. 2003. The network paradigm in organizational research: a review and typology. Journal of Management 29(6):991-1013. http://dx.doi.org/10.1016/ S0149-2063 03 00087-4

Carlsson, L. G., and A. C. Sandström. 2008. Network governance of the commons. International Journal of the Commons 2(1):33-54. [online] URL: http://www.thecommonsjournal. org/index.php/ijc/article/viewArticle/20

Clark, M., and M. Ayers. 1992. Friendship similarity during early adolescence: gender and racial patterns. Journal of Psychology 126(4):393-405. http://dx.doi.org/10.1080/00223980.1992.10543372

Costello, C., S. D. Gaines, and J. Lynham. 2008. Can catch shares prevent fisheries collapse? Science 321(5896):1678-1681. http://dx.doi.org/10.1126/science.1159478

Crona, B. I. 2006. Supporting and enhancing development of heterogeneous ecological knowledge among resource users in a Kenyan seascape. Ecology and Society 11(1): 32. [online] URL: http://www.ecologyandsociety.org/vol11/iss1/art32/
Crona, B., and Ö. Bodin. 2006. What you know is who you know? Communication patterns among resource users as a prerequisite for co-management. Ecology and Society 11(2): 7. [online] URL: http://www.ecologyandsociety.org/vol11/ iss2/art7/

Crowe, J. A. 2007. In search of a happy medium: how the structure of interorganizational networks influence community economic development strategies. Social Networks 29 (4):469-488. http://dx.doi.org/10.1016/j.socnet.2007.02.002

Currarini, S., M. O. Jackson, and P. Pin. 2009. An economic model of friendship: homophily, minorities, and segregation. Econometrica 77(4):1003-1045. http://dx.doi.org/10.3982/ ECTA7528

Davies, S. 2012. 9th Circuit approves of Hawaii longline consent decree. Endangered Species and Wetland Report, 15 March. [online] URL: http://www.eswr.com/2012/03/9thcircuit-approves-of-hawaii-longline-consent-decree/

Dietz, T., E. Ostrom, and P. C. Stern. 2003. The struggle to govern the commons. Science 302(5652):1907-1912. http:// dx.doi.org/10.1126/science.1091015

DuBois, D. L., and B. J. Hirsch. 1990. School and neighborhood friendship patterns of Blacks and Whites in early adolescence. Child Development 61(2):524-536. [online] URL: http://www.jstor.org/stable/1131112

Ehrlich, P. R., and S. A. Levin. 2005. The evolution of norms. PLoS Biology 3(6):e194. http://dx.doi.org/doi:10.1371/ journal.pbio.0030194

García-Amado, L. R., M. R. Pérez, I. Iniesta-Arandia, G. Dahringer, F. Reyes, and S. Barrasa. 2012. Building ties: social capital network analysis of a forest community in a biosphere reserve in Chiapas, Mexico. Ecology and Society 17(3): 3. [online] URL: http://www.ecologyandsociety.org/vol17/iss3/ art3/

Grafton, R. Q. 2005. Social capital and fisheries governance. Ocean \& Coastal Management 48(9-10):753-766. http://dx. doi.org/10.1016/j.ocecoaman.2005.08.003

Granovetter, M. 1985. Economic action and social structure: the problem of embeddedness. American Journal of Sociology 91(3):481-510. [online] URL: http://www.jstor.org/stable/2780199

Gray, S., A. Chan, D. Clark, and R. Jordan. 2012a. Modeling the integration of stakeholder knowledge in social-ecological decision-making: benefits and limitations to knowledge diversity. Ecological Modelling 229:88-96. http://dx.doi. org/10.1016/j.ecolmodel.2011.09.011

Gray, S., R. Shwom, and R. Jordan. 2012b. Understanding factors that influence stakeholder trust of natural resource science and institutions. Environmental Management 49 (3):663-674. http://dx.doi.org/10.1007/s00267-011-9800-7 
Gutiérrez, N. L., R. Hilborn, and O. Defeo. 2011. Leadership, social capital and incentives promote successful fisheries. Nature 470:386-389. http://dx.doi.org/10.1038/nature09689

Haas, M., editor. 1998. Multicultural Hawai'i: the fabric of a multiethnic society. Garland, New York, New York, USA.

Hahn, T., P. Olsson, C. Folke, and K. Johansson. 2006. Trustbuilding, knowledge generation and organizational innovations: the role of a bridging organization for adaptive comanagement of a wetland landscape around Kristianstad, Sweden. Human Ecology 34(4):573-592. http://dx.doi. org/10.1007/s10745-006-9035-Z

Hanneman, R. A., and M. Riddle. 2005. Introduction to social network methods. University of California, Riverside, California, USA. [online] URL: http://faculty.ucr.edu/ hanneman/nettext/

Isaac, M. E., B. H. Erickson, S. J. Quashie-Sam, and V. R. Timmer. 2007. Transfer of knowledge on agroforestry management practices: the structure of farmer advice networks. Ecology and Society 12(2): 32. [online] URL: http:// www.ecologyandsociety.org/vol12/iss2/art32/

Krackhardt, D., and R. N. Stern. 1988. Informal networks and organizational crises: an experimental simulation. Social Psychology Quarterly 51(2):123-140. http://dx.doi. org/10.2307/2786835

Kubota, G. T. 2012. Fisheries Service pressed to protect false killer whales. Star-Advertiser, Honolulu, 13 August. [online] URL: http://www.staradvertiser.com/s?action=login\&f= y\&id $=165947666$

Marín, A., and F. Berkes. 2010. Network approach for understanding small-scale fisheries governance: the case of the Chilean coastal co-management system. Marine Policy 34 (5):851-858. http://dx.doi.org/10.1016/j.marpol.2010.01.007

McCay, B. J., and S. Jentoft. 1996. From the bottom up: participatory issues in fisheries management. Society \& Natural Resources 9(3):237-250. http://dx.doi. org/10.1080/08941929609380969

McPherson, M., L. Smith-Lovin, and J. M. Cook. 2001. Birds of a feather: homophily in social networks. Annual Review of Sociology 27:415-444. http://dx.doi.org/10.1146/annurev. $\underline{\text { soc.27.1.415 }}$

Miguel, E., and M. K. Gugerty. 2005. Ethnic diversity, social sanctions, and public goods in Kenya. Journal of Public Economics 89(11-12):2325-2368. http://dx.doi.org/10.1016/ j.jpubeco.2004.09.004

National Oceanic and Atmospheric Administration (NOAA). 2006. Magnuson-Stevens Fishery Conservation and Management Reauthorization Act of 2006, Public Law no. 109-479, 120 Stat 3575 (2006). NOAA, Washington, D.C., USA.
National Oceanic and Atmospheric Administration (NOAA). 2012. The Hawaii-based longline logbook summary reports, January - December 2011. Pacific Islands Fisheries Science Center, NOAA National Marine Fisheries Service, Honolulu, Hawaii, USA. [online] URL: http://www.pifsc.noaa.gov/fmb/ reports.php

Newman, L., and A. Dale. 2007. Homophily and agency: creating effective sustainable development networks. Environment, Development and Sustainability 9(1):79-90. http://dx.doi.org/10.1007/s10668-005-9004-5

Nordyke, E. C. 1989. The peopling of Hawai' $i$. University of Hawaii Press, Honolulu, Hawaii, USA.

Oh, H., M. H. Chung, and G. Labianca. 2004. Group social capital and group effectiveness: the role of informal socializing ties. Academy of Management Journal 47 (6):860-875. [online] URL: http://www.jstor.org/stable/20159627

Ostrom, E. 1990. Governing the commons: the evolution of institutions for collective action. Cambridge University Press, Cambridge, UK. http://dx.doi.org/10.1017/CBO9780511807763

Ostrom, E., R. Gardner, and J. Walker. 1994. Rules, games, and common-pool resources. University of Michigan Press, Ann Arbor, Michigan, USA.

Pan, M., P. S. Leung, and S. G. Pooley. 2001. A decision support model for fisheries management in Hawaii: a multilevel and multiobjective programming approach. North American Journal of Fisheries Management 21(2):293-309. http://dx.doi.org/10.1577/1548-8675(2001)021<0293:ADSMFF >2.0. $\mathrm{CO} ; 2$

Pinto da Silva, P., and A. Kitts. 2006. Collaborative fisheries management in the Northeast US: emerging initiatives and future directions. Marine Policy 30(6):832-841. http://dx.doi. org/10.1016/j.marpol.2006.04.003

Pomeroy, R., J. Parks, R. Pollnac, T. Campson, E. Genio, C. Marlessy, E. Holle, M. Pido, A. Nissapa, S. Boromthanarat, and T. H. Nguyen. 2007. Fish wars: conflict and collaboration in fisheries management in Southeast Asia. Marine Policy 31 (6):645-656. http://dx.doi.org/10.1016/j.marpol.2007.03.012

Portes, A., and J. Sensenbrenner. 1993. Embeddedness and immigration: notes on the social determinants of economic action. American Journal of Sociology 98(6):1320-1350. http://dx.doi.org/10.1086/230191

Poteete, A. R., and E. Ostrom. 2004. Heterogeneity, group size and collective action: the role of institutions in forest management. Development and Change 35(3):435-461. http:// dx.doi.org/10.1111/j.1467-7660.2004.00360.x

Prell, C. 2009. Linking social capital to small-worlds: a look at local and network-level processes and structure. Methodological Innovations Online 4(1):8-17. 
Prell, C., K. Hubacek, C. Quinn, and M. Reed. 2008. 'Who's in the network?' When stakeholders influence data analysis. Systemic Practice and Action Research 21(6):443-458. http:// dx.doi.org/10.1007/s11213-008-9105-9

Prell, C., M. Reed, and K. Hubacek. 2011. Social network analysis for stakeholder selection and the links to social learning and adaptive co-management. Pages 95-118 in Ö. Bodin and C. Prell, editors. Social networks and natural resource management: uncovering the social fabric of environmental governance. Cambridge University Press, Cambridge, UK. http://dx.doi.org/10.1017/CBO9780511894985.006

Pretty, J. 2003. Social capital and the collective management of resources. Science 302(5652):1912-1914. http://dx.doi. org/10.1126/science.1090847

Ramirez-Sanchez, S. 2011a. Who and how: engaging wellconnected fishers in social networks to improve fisheries management and conservation. Pages 119-146 in Ö. Bodin and C. Prell, editors. Social networks and natural resource management: uncovering the social fabric of environmental governance. Cambridge University Press, Cambridge, UK. http://dx.doi.org/10.1017/CBO9780511894985.007

Ramirez-Sanchez, S. 2011b. The role of individual attributes in the practice of information sharing among fishers from Loreto, BCS, Mexico. Pages 234-254 in Ö. Bodin and C. Prell, editors. Social networks and natural resource management: uncovering the social fabric of environmental governance. Cambridge University Press, Cambridge, UK. http://dx.doi. org/10.1017/CBO9780511894985.011

Ramirez-Sanchez, S., and E. Pinkerton. 2009. The impact of resource scarcity on bonding and bridging social capital: the case of fishers' information-sharing networks in Loreto, BCS, Mexico. Ecology and Society 14(1): 22. [online] URL: http:// www.ecologyandsociety.org/vol14/iss 1/art22/

Romani, M. 2003. Love thy neighbor? Evidence from ethnic discrimination in information sharing within villages in Côte d'Ivoire. Journal of African Economies 12(4):533. http://dx. doi.org/10.1093/jae/12.4.533

Rova, C. 2004. Flipping the pyramid: lessons from converting top-down management of bleak row fisheries. Dissertation. Lulea University of Technology, Lulea, Sweden.

Ruttan, L. M. 2006. Sociocultural heterogeneity and the commons. Current Anthropology 47(5):843-853. [online] URL: http://www.jstor.org/discover/10.1086/507185? uid $=3739464 \&$ uid $=2 \& u i d=3737720 \&$ uid $=4 \&$ sid $=21101680776161$

Sandström, A. C., and C. V. Rova. 2010. The network structure of adaptive governance: a single case study of a fish management area. International Journal of the Commons 4 (1):528-551. [online] URL: http://www.thecommonsjournal. org/index.php/ijc/article/viewArticle/156
Schofield, J. W. 1979. The impact of positively structured contact on intergroup behavior: does it last under adverse conditions? Social Psychology Quarterly 42(3):280-284. [online] URL: http://www.jstor.org/stable/3033772

Schofield, J. W. 1991. School desegregation and intergroup relations: a review of the literature. Review of Research in Education 17:335-409. [online] URL: http://www.jstor.org/ stable/1167335

Smith, A., and B. H. Schneider. 2000. The inter-ethnic friendships of adolescent students: a Canadian study. International Journal of Intercultural Relations 24 (2):247-258. http://dx.doi.org/10.1016/S0147-1767(99)00034-6

Snijders, T. A. B., P. E. Pattison, G. L. Robins, and M. S. Handcock. 2006. New specifications for exponential random graph models. Sociological Methodology 36(1):99-153. http:// dx.doi.org/10.1111/j.1467-9531.2006.00176.x

Tajfel, H., and J. C. Turner. 1979. An integrative theory of intergroup conflict. Pages 33-47 in W. G. Austin and S. Worchel, editors. The social psychology of intergroup relations. Brooks-Cale, Monterey, California, USA.

U.S. Census Bureau. 2012. Annual estimates of the resident population: April 1, 2010 to July 1, 2011. U.S. Census Bureau, Population Division, Washington, D.C., USA.

Valente, T. W. 2012. Network Interventions. Science 337 (6090):49-53. http://dx.doi.org/10.1126/science.1217330

Varughese, G., and E. Ostrom. 2001. The contested role of heterogeneity in collective action: some evidence from community forestry in Nepal. World Development 29 (5):747-765. http://dx.doi.org/10.1016/S0305-750X(01)00012-2

Waring, T. M. 2011. Ethnic forces in collective action: diversity, dominance, and irrigation in Tamil Nadu. Ecology and Society: 16(4): 1. http://dx.doi.org/10.5751/ES-04265-160401

Western Pacific Fisheries Information Network (WPacFIN). 2012. Chart and tabulated values of the Hawaii 1989-2011 CPI adjusted revenue of all pelagic species by fishery (\$1000). Pacific Islands Fisheries Science Center, NOAA National Marine Fisheries Service, Honolulu, Hawaii, USA. [online] URL: http://www.pifsc.noaa.gov/wpacfin/hi/Data/Pelagic/ hpel4.htm

Wilson, C. 2009. Hawaii's DLNR shifts its enforcement focus. Honolulu Advertiser, 9 June. [online] URL: http://the. honoluluadvertiser.com/article/2009/Jun/29/1n/hawaii906290346. $\underline{\mathrm{html}}$

Woolcock, M. 2001. The place of social capital in understanding social and economic outcomes. Canadian Journal of Policy Research 2(1):11-17. 


\section{Appendix 1. Data Collection and Survey Questions}

Though we developed a survey-questionnaire that could have been filled out by respondents if they chose, the majority of our data was collected via face-to-face interviews in the primary language of each fisher. Respondents were first asked to participate, and then asked a few general warm up questions regarding their position in the fishery and their experience fishing. Respondents were then asked to nominate at least five, but up to ten people with whom they share useful information regarding different aspects of fishing within the HLF that they felt was valuable for their fishing success. Respondents were prompted to consider relationships that they might have with vessel owners, captains, supply store owners or other industry leaders, government/management officials, and members of the scientific community. Respondents were also asked to consider relationships they might have with fishers or other actors from different ethnic backgrounds. General sociodemographics and ethnic association were also collected. $100 \%$ of K-A and V-A fishers self-identified as either Korean or Vietnamese (respectively). The majority of E-A fishers self-identified as 'Caucasian' or 'American' when asked their ethnicity, while some E-A fishers reported European ancestry. A limited number of questionnaires were sent and returned via mail and email to owners currently living on the mainland U.S., outside of the study area. When this was the case, a cover letter was attached describing the study and study aim. Our survey used the following format to gain insight into the nature of each relationship identified, and left ten open spaces for respondents to identify individuals in their network:

$\begin{array}{llrl}\text { I. } \frac{\text { (name of individual) }}{\text { professional acquaintance }} \text { friend } & \text { family member } \\ \text { very strong } & \text { strong } & \text { weak } & \text { very weak }\end{array}$

A. How did you meet this person?

$\square$ family member $\square$ through fishing $\square$ from a friend

$\square$ from a family member $\square$ other:

B. How often do you share useful information about aspects of fishing with this person?

Not often (1-3 times/yr.) a Sometimes (1-3 times/mo.) a A lot (1-3 times/wk. or more)

C. What do you typically talk to this person about? (check all that apply)
$\square$ gear type
$\square$ weather conditions
$\square$ site catch/location
fish activity
bycatch/turtle activity
$\square$ vessel technology/maintenance
fishery regulations
$\square$ hiring of crew/captain

D. In general, how valuable would you say the information that you share with this person is to your fishing success?

$\square$ Very valuable

Somewhat valuable

Not valuable 